\title{
A THREE-YEAR PROSPECTIVE STUDY OF STREPTO- COCCAL INFECTIONS IN A POPULATION OF RURAL EGYPTIAN SCHOOL CHILDREN
}

\author{
A. El Kholy, A. H. Sorour, H. B. Houser*, L. W. Wannamaker $\dagger$, \\ M. Robins $\ddagger$ J.-M. Poitras§ AND R. M. KRause\| \\ The Rheumatic Fever Project, Post Office Box 424, Cairo, Egypt
}

Numerous epidemiological studies have defined the incidence, mode of spread, and clinical pattern of streptococcal diseases in Europe (Szita and Hegyessy, 1966; Ivan et al., 1967; Rotta et al., 1968) and the North American continent (Wannamaker, 1954; Saslaw and Streitfeld, 1956; Quinn, Denny and Riley, 1957; Rammelkamp, 1957; Houser, 1969), but there is inadequate similar information for middle eastern countries with the exception of Israel (Davies et al., 1968; Halfon et al., 1968). In Egypt and elsewhere in the Middle East (Abdin and Eissa, 1965; Davies et al.; Sorour and El Kholy, 1969; Sorour, El Kholy and Shahin, $1969 a$ and $b$ ), clinicians report the occurrence of rheumatic fever and rheumatic heart disease, an indication that streptococcal infections are present in the population.

The present study was designed to define the incidence of streptococcal disease in a school-child population in a rural village in Egypt. Epidemiological and clinical features were also examined. Because Siegel, Johnson and Stollerman (1961) have suggested that prominent exudative tonsillitis is not a constant or reliable feature of endemic streptococcal pharyngitis in children, special attention was given to the detection of streptococcal acquisitions by bacteriological and serological means in addition to physical examination.

\section{MATERIALS AND METHODS}

The population of a primary school in the Qalyub district, $20 \mathrm{~km}$ north of Cairo, Arabian Republic of Egypt, was observed for the occurrence of streptococcal infections from 1967 to 1970. The total enrolled school population is approximately 300 children aged 6 to $12 \mathrm{yr}$. Because sociological conditions led to irregular attendance, only 156 school children could be observed with reasonable frequency during the 3-yr period of observation. The average absentee rate at the time of monthly observation was 30 per cent. The analysis of the data pertains to this group only.

Received 7 July 1972; accepted 3 Aug. 1972.

* Present address: Department of Biometry, School of Medicine, Case Western Reserve University, Cleveland, Ohio 44106, USA.

$\uparrow$ Present address: Department of Pediatrics, The University of Minnesota, School of Medicine, Minneapolis, Minnesota 55455, USA.

$\ddagger$ Present address: Health Services and Mental Health Administration, Parklawn Building, Rockville, Maryland 20852, USA.

$\S$ Present address: 107 Edgerton Road, Towson, Maryland 21204, USA.

II Present address: The Rockefeller University, New York, New York 10021, USA.

Please address reprint requests to R. M. K.

J. MED. MICROBIOL.-VOL. 6 (1973) 
Observations made included: monthly throat swabs for group-A streptococci; the serial assessment of the antibody response to streptolysin $\mathrm{O}$ at least 6-monthly and in some instances more frequently; and weekly clinical observations.

Throat cultures were taken by swabbing both tonsils and tonsillar fossae with sterile disposable synthetic-fibre swabs which were inoculated immediately on to 6 per cent. sheep blood agar plates prepared with Difco Blood Agar Base. After 18 hours' incubation at $37^{\circ} \mathrm{C}$, a single $\beta$-haemolytic streptococcal colony was picked and identified by microscopic examination of Gram-stained material. Streptococcal isolates were than grouped by the acid extraction method (Lancefield, 1933). Rabbit grouping antisera were prepared locally; their potency and specificity were checked against reference stock sera obtained from the WHO Reference Laboratory, Prague, and the Central Public Health Laboratory, Colindale, London.

Group-A streptococci were stored for a variable period of time in blood broth at $-20^{\circ} \mathrm{C}$ for subsequent $\mathrm{T}$ typing. $\mathrm{T}$ typing was performed by the slide-agglutination technique (Griffith, 1934; Padula, Facklam and Moody, 1969). Rabbit antisera were prepared against the following $\mathrm{T}$ antigens: $1,2,3,4,5,6,8,9,11,12,13,14,22,25,27,28,44, \mathrm{~B} 3264$, and Imp. 19. All positive agglutinations were blindly rechecked by a second examiner. Retyping of isolates was done in case of discrepancies, which occurred in 2 per cent. of the cases on first trial. Ninety per cent. of group-A isolates were identified by the T-type antisera.

A sample of the group-A streptococci were tested with unabsorbed M-type antisera by the double-diffusion technique described by Rotta et al. (1971).

The ASO determinations were made by the Rantz and Randall procedure (1945) on inactivated sera that had been stored at $-20^{\circ} \mathrm{C}$ for various periods of time. Blood samples were taken 11 times during the period of observation. Twenty-five per cent. of all determinations were repeated to assess the reproducibility of the values obtained. The coefficient of correlation was $\mathbf{0 . 8 6}$ and less than 1 per cent. of the values showed a difference of two or more tubes.

\section{RESULTS}

\section{Carrier studies}

Only 30 per cent. of all the $\beta$-haemolytic streptococci isolated from the throat were members of group A as identified by the Lancefield method. Most of the remainder belonged to groups $\mathrm{C}$ and $\mathrm{G}$; the significance of this finding has yet to be determined.

In fig. 1 are represented the throat carrier-rates of group-A streptococci by months for the 156 school-age children (aged 6-12 yr) who were followed for this 3 -yr period. There is a general increase in the percentage of carriers from 1967 to 1970. Part of this increase might be due to improvement in our isolation techniques, but this is unlikely because the laboratory had been in operation for 2 yr before 1967. Methods, techniques, material and staff were unchanged during the whole period of bacteriological surveillance. The average yearly rate of group-A carriers was 13 per cent. in 1967-68, 19 per cent. in 1968-69, and 24 per cent. in 1969-70. There is a statistically significant difference $(\mathrm{P}<0.05)$ between the 1967-68 rates and those of the following 2 yr. During the last 2 yr a sharp rise occurred during the autumn and winter with a subsequent gradual fall. This did not occur during 1967-68. An extension of the observations beyond this 3-yr period will be required to determine whether there is a periodicity to these yearly fluctuations in the carrier rates, or whether the annual epidemics were due to the introduction of new types into the study population.

The seasonal variations show a general pattern in which the highest monthly 
carrier rate occurred during the late autumn and early winter and the minimal rate in the summer months. However, the pattern is punctuated with small variations in the rate occurring at different times from one year to another

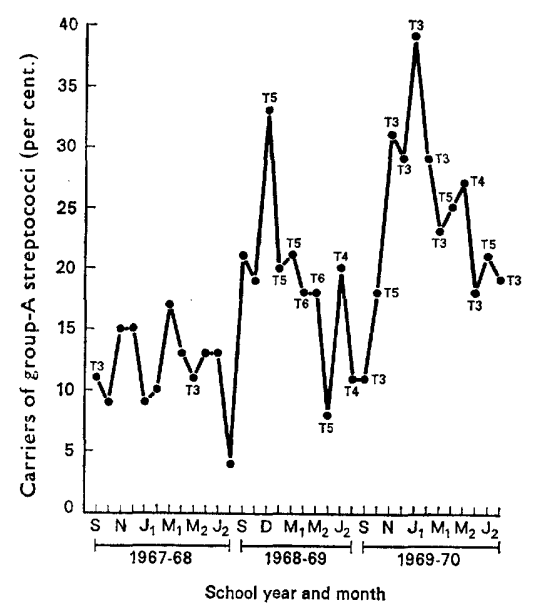

FIG. 1.-Throat carrier-rates of group-A streptococci by months for 156 school children aged 6-12 yr. $\mathrm{S}=$ Sept., $\mathbf{N}=$ Nov., $\mathbf{D}=$ Dec., $\mathrm{J}_{1}=\mathrm{Jan}_{\text {. }}, \mathbf{M}_{1}=$ Mar., $\mathbf{M}_{2}=$ May, $\mathrm{J}_{2}=$ July. Cultures were not taken in Oct. 1968 and Feb. 1969. T3, T4, T5, T6: predominant T-typing pattern among group-A streptococci isolated in the month; see table I.

TABLE I

Distribution of T-typing patterns among group- $A$ streptococci isolated from 156 school children in the years 1968-69 and 1969-70

\begin{tabular}{|c|c|c|c|c|c|c|c|c|c|c|c|c|c|}
\hline \multirow{3}{*}{$\begin{array}{l}\text { School } \\
\text { year }\end{array}$} & \multicolumn{13}{|c|}{ Number of isolations } \\
\hline & \multicolumn{11}{|c|}{ with T-typing pattern* } & \multirow{2}{*}{$\begin{array}{l}\text { Total T } \\
\text { typable }\end{array}$} & \multirow[b]{2}{*}{ Untypable } \\
\hline & 1 & 2 & 3 & 4 & 5 & 6 & 8 & 9 & 14 & 22 & 23 & & \\
\hline $1968-69$ & 6 & 2 & 24 & 23 & 41 & 25 & 18 & 4 & 11 & 2 & 11 & 167 & 31 \\
\hline $1969-70$ & 20 & 2 & 69 & 16 & 56 & 1 & 26 & 4 & 1 & $\ldots$ & 13 & 208 & 38 \\
\hline Both years & 26 & 4 & 93 & 39 & 97 & 26 & 44 & 8 & 12 & 2 & 24 & 375 & 69 \\
\hline
\end{tabular}

* Patterns T3, T5 and T8 include respectively strains that were agglutinated by one or more $\mathrm{T}$ antisera of the following series: 3,13 and $\mathrm{B} 3264 ; 5,11,12,27$ and 44; 8, 25 and Imp. 19.

during the spring and early summer. The major seasonal variation in the monthly rate is similar to that reported for primary-school populations in the USA, Europe and Israel (Davies et al.; Halfon et al; Rotta et al., 1968; Saslaw and Streitfeld).

Slide agglutination was employed to determine the T-typing pattern of all group-A strains isolated in 1968-70 and of a sample of those isolated in 1967-68. 
The dominant pattern found in each month is indicated in fig. 1, and the Ttyping results for 1968-70 are presented in table I. For simplicity T-typing patterns are indicated by the first number in the pattern. It is to be noted that during the months of 1968-69 when carrier rates were highest, pattern T5 was predominant, whereas $\mathrm{T} 3$ was the predominant pattern for the corresponding period in 1969-70. Other patterns were dominant during the months when there were irregular fluctuations in the carrier rates. For example, pattern T4 was predominant during July 1969 with a concomitant rise in the carrier rate, perhaps denoting a minor epidemic during this period.

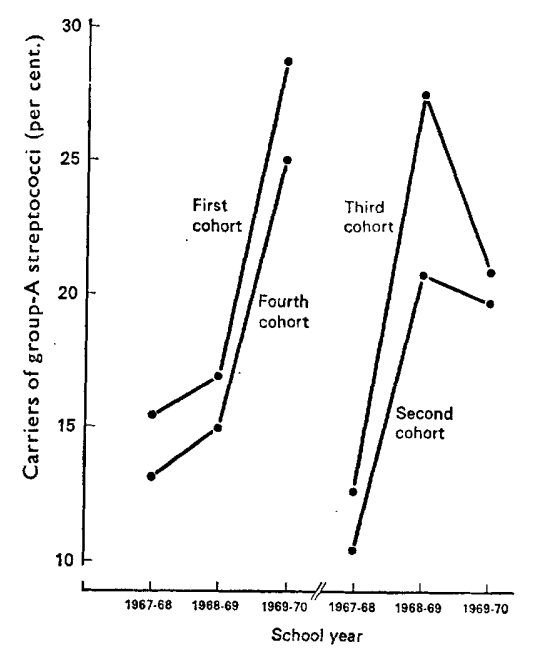

FIG. 2.-Carrier rates throughout 3 school years for four cohorts of children. The figures shown are the averages of the monthly carrier rates for each school grade.

In fig. 2 is presented a cohort analysis of the carrier rates throughout the $3 \mathrm{yr}$ for four groups of children. At the onset of this study, cohort 1 was in the first grade (i.e., the youngest school class), cohort 2 was in the second grade, cohort 3 was in the third grade, and cohort 4 was in the fourth grade. The yearly rates expressed here are averages of the monthly rates for each group for each 12-mth period. The children in cohorts 1 and 4 had the same relatively low carrier rates in 1967-68 and 1968-69, and a parallel increase in the carrier rate in 1969-70. The children in cohorts 2 and 3, on the other hand, had a striking increase in the rate between 1967-68 and 1968-69, but some decrease in 1969-70. The independent fluctuation of rates in the four cohort populations suggests that the classroom is more important than other areas of the school as the locus of exposure and transmission. This is consistent with the view that direct respiratory contact spread is the major mechanism of transmission of streptococci and emphasises the role of person-to-person contact in the spread of streptococcal infections.

From the long-term observations of this population it has been possible to assess the persistence of the group-A streptococcal carrier state. In the same 11 children ( 7 per cent.) there was a very frequent recovery of group-A streptococci throughout the 3-yr period, whereas in another group of 20 children 
(13 per cent.), group-A streptococci were never or seldom isolated. For the majority, however, there were yearly variations in the frequency of recovery of streptococci. These variations are presented in detail in the quartile analysis depicted in table II.

The children were classified into " high ", " low", and " negative " groups on the basis of the number of isolations in 1967-68. The group designated

TABLE II

The yearly distribution of the study population into groups* with different isolation rates of group- $A$ streptococci

A. Comparison of isolation rates in 1967-68 and 1968-69

\begin{tabular}{l|ccc}
\hline \multirow{2}{*}{$\begin{array}{l}\text { Isolation rate } \\
\text { in 1967-68 }\end{array}$} & \multicolumn{3}{c}{$\begin{array}{c}\text { Percentage of children whose isolation } \\
\text { rate in 1968-69 was }\end{array}$} \\
\cline { 2 - 3 } high & low & negative \\
High & $52 \dagger$ & 23 & 25 \\
Low & 28 & $39 \dagger$ & 33 \\
Negative & 24 & 37 & $39 \dagger$ \\
\hline
\end{tabular}

B. Comparison of isolation rates in 1968-69 and 1969-70

\begin{tabular}{l|ccc}
\hline $\begin{array}{c}\text { Isolation rate } \\
\text { in 1968-69 }\end{array}$ & \multicolumn{2}{c}{$\begin{array}{c}\text { Percentage of children whose isolation } \\
\text { rate in 1969-70 was }\end{array}$} \\
\hline high & low & negative \\
Low & $42 \dagger$ & 40 & 18 \\
Negative & 33 & $35 \dagger$ & 32 \\
\hline
\end{tabular}

* The high, low and negative groups are defined in the text.

$\uparrow$ Remained in the same group for two consecutive years.

" high frequency" of isolations in table II were those above the fiftieth percentile. The group designated " low frequency" of isolation were those below the fiftieth percentile. The third group in the table, designated "negative", are those children from whom no group-A streptococcal isolations were made. Differences in carrier rate between the high and low groups were significant $(\mathrm{P}<0.05)$.

From one year to the next, 60 per cent. of the children showed variations in the frequency of recovery of group-A streptococci and moved from one group to another. Thus 24 per cent. of the children in the negative group in 1967-68 were in the high-frequency group in 1968-69, and conversely 25 per cent. of the children in the high-frequency group in 1967-68 were in the negative group in 1968-69. 
In any calendar year, children in a particular grade were of about the same age as those in the same grade in previous or subsequent years. Because the carrier rates were related to the cohort rather than to the grade itself, it appears that age was not the determining factor in the carrier rates.

\section{Evidence for streptococcal infection}

Monthly history and clinical examinations indicated a very low occurrence of typical acute exudative streptococcal pharyngitis. A follow-up programme was initiated to examine those who were absent from school at the time the monthly observations were made. There was no clinical evidence of acute exudative pharyngitis in these children.

In the absence of clinically recognisable exudative streptococcal pharyngitis, bacteriological and serological data were employed to determine the attack rates of streptococcal infections. Monthly sera were collected on the children from November 1968 to May 1969. The total possible person-months of observation was 1248; because of absentees, this analysis was limited to 945 person-months during which consecutive monthly cultures had been taken and consecutive monthly sera collected. The isolation of streptococci in any of two sequential months preceding a rise in the ASO titre of two tubes or greater was considered an indication of a streptococcal infection. In these 945 personmonths of observation there were 25 streptococcal infections, giving an attack rate of 6 per 1000 per week. The actual attack rate was probably greater than this, because there were an additional 36 ASO rises in patients with a negative throat culture in the month in which the ASO rose above previous levels and in the immediately preceding month. Only four children had more than one streptococcal infection during this 7 -mth period.

Streptococci with T patterns T4, T6, T8 and T23 caused 68 per cent. of the infections; 32 per cent. were due to T3 and T5 streptococci. Fifty per cent. of the carrier strains were T3 and T5. M-typing was performed on 28 isolates from patients who subsequently developed an ASO response. Fifteen strains were M-typable; the types detected included 2, 6, 13, 14, 18, 19, 24, 29 , and 41 .

\section{DISCUSSION}

The occurrence of streptococcal infections and their non-suppurative complications has remained largely unrecorded in many countries of the world, including Egypt. We therefore began $5 \mathrm{yr}$ ago to examine the epidemiological and clinical patterns of streptococcal diseases in a rural suburb of Cairo, and made monthly clinical and bacteriological observations on 156 Egyptian school children over the last $3 \mathrm{yr}$ of this period. In an analysis confined to $7 \mathrm{mth}$ of 1970 , the total attack rate of streptococcal pharyngeal infections was 6 per 1000 per week. This was based on the isolation of group-A streptococci from the throat and a concomitant rise in ASO titre. The rate is higher than that reported for the family study in Cleveland (Dingle, 1959), but other school populations in the United States (Schneider et al., 1964) have had rates similar to those in Egypt. Another indication that streptococcal infections 
are common occurrences in Egypt is the prevalence rate of rheumatic heart disease of 1.5 per cent. for children between 6 and $12 \mathrm{yr}$ of age (Sorour and El Kholy, 1969).

A recent report of the World Health Organization Expert Committee on Streptococcal and Staphylococcal Infections (1968) raised the possibility that the disease patterns, and indeed the mechanisms of spreading infections, may differ in Africa, Asia and Central America from those observed in temperate climates. In general, from the evidence presented, this would not appear to be the case in Egypt, but a possible difference may be in the unusually mild nature of streptococcal pharyngitis here. In no instance, for example, was a child seen with exudative pharyngitis similar to that reported among U.S. servicemen at Warren Air Force Base, Wyoming (Krause et al., 1962). It should be stressed, however, that exudate is a less reliable indicator of streptococcal pharyngitis in children than it is in adults (Kaplan et al., 1971).

There are still insufficient data to define in complete detail the mechanisms of transmission of streptococcal disease among Egyptian school children, but the pattern that emerges from these initial studies parallels that observed in similar populations in temperate climates. Over a 3-yr period, carriage rates and streptococcal infections increased in the autumn and winter and declined in the summer, a pattern suggesting spread primarily by the respiratory route. The carrier rates of each of four school grades in the same school varied independently, an indication that the schoolroom is the major locus for transmission. Levine et al. (1966) have emphasised the importance of intrafamilial transmission of streptococci in addition to spread in classrooms. While it was not possible to study the role of the family in the spread of streptococcal disease, such studies are now in progress.

The monthly bacteriological studies for a 3-yr period on 156 school-age children provides an assessment of the nature of the pharyngeal group-A carrier state. In 7 per cent. of the children, 25 per cent. or more of the monthly throat cultures were positive. At the other extreme, 13 per cent. of the children had less than 5 per cent. of their throat cultures positive. Further data must be collected to determine whether such extremes are a reflection of familial susceptibility or of resistance to streptococcal carriage, as suggested by Zimmerman and Wilson (1968). For most of the children, however, there were marked shifts in the percentage of positive monthly throat cultures from one year to the next. Such fluctuations suggest a periodicity in the acquisition of the streptococcal carriage, but the time-span of such periodicity has yet to be determined.

Monthly throat and ASO determinations provided an assessment of the occurrence of streptococcal infections in this population, but it should be emphasised that an antibody response to only a single antigen (streptolysin $\mathrm{O}$ ) was measured. From other studies undertaken on the same asymptomatic children (unpublished data) the measurement of another antibody response (anti-DNAase B) increased the yield of streptococcal infections by 25 to 40 per cent. This improvement in case finding by the use of an additional test is greater than that found by Kaplan et al. among children with pharyngitis. 
In spite of laboratory evidence for the prevalence of streptococcal infections, the low frequency of clinical pharyngitis was striking. Streptococcal infections appear to be unusually mild and exudate is very rarely seen.

The children who became carriers of group-A streptococci but did not show a subsequent rise in ASO had an initial ASO titre of 134 Todd units. This was significantly higher than the initial ASO titre of 76 units in the group of children with an observed rise in ASO and a positive throat culture. Similar findings were also found by Kaplan et al. among symptomatic children with pharyngitis.

There were 36 instances of a rise in ASO without a positive throat culture in the preceding 2-mth period. In this group the initial mean ASO titre was 82 and the subsequent titre was 209 . Fourteen of these children harboured haemolytic streptococci of groups $C$ and $G$ in the throat, whereas the 16 remaining children had negative throat cultures for all $\beta$-haemolytic streptococci. In the latter group the antibody responses were possibly due to a group-A streptococcal infection of the skin or elsewhere. Alternatively, the ASO rise may in some cases have been due to the acquisition of other bacteria that produce a streptolysin $\mathrm{O}$ serologically similar to that of groups $\mathrm{A}$ and $\mathrm{C}$ streptococci (Bernheimer, in press), even though clinical and epidemiological experience elsewhere suggest that this does not occur in man (Sugihara and Squier, 1951).

\section{SUMMARY}

Epidemiological and clinical observations on streptococcal infections in 156 Egyptian school children aged 6 to $12 \mathrm{yr}$ were obtained by prospective bacteriological, serological and clinical surveys from 1967 to 1970 .

The yearly recovery rate of group-A streptococci from the throat varied from 13 per cent. to 24 per cent. The seasonal variations showed a peak during the late autumn and winter and a minimal rate in the summer months. The carrier rate in each of four school grades varied independently, an indication that the classroom, more than any other area of the school, is a primary locus of exposure and transmission.

The prevalence of the group-A streptococcal carrier state was assessed from the long-term observation of the study population. In 7 per cent. of the children, more than 25 per cent. of the monthly throat cultures were positive in a 3-yr period. Thirteen per cent. of the children had fewer than 5 per cent. of throat cultures positive. In most of the children, however, there were marked shifts in the percentage of positive monthly throat cultures from one year to the next.

The attack rate of streptococcal infections, defined as a throat culture positive for group-A streptococci with a concomitant rise of ASO, was 6 per 1000 per week.

Supported by a research grant, P.L. 480-03-801-2 from the U.S. Public Health Service.

\section{REFERENCES}

ABDIN, Z. H., AND EISSA, A. 1965. Rheumatic fever and rheumatic heart disease in children below 5 years of age in the tropics. Ann. Rheum. Dis., 24, 389. 
Bernheimer, A. W. 1972. Hemolysin of streptococci; characterization, including effect on biological membranes. In Continuation medical course in streptococci and their diseases, edited by L. W. Wannamaker and J. Matsen, New York, p. 19.

Davies, A. M., Brandt-Auraban, A., Szabo, M., Halfon, S. T., and Bergner-RabinoWITZ, SonIA 1968. Primary prevention of rheumatic fever in Jerusalem school children. I. Rationale and results of the pilot study. Israel J. Med., Sci., 4, 801.

Dingle, J. H. 1959. An epidemiological study of illness in families. Harvey Lect. 1957$1958,53,1$.

GrifFIrH, F. 1934. The serological classification of Streptococcus pyogenes. J. Hyg., Camb., $34,482$.

Halfon, S. T., Davies, A. M., Kaplan, O., Lazarov, E., and Bergner-Rabinowitz, Sonia 1968. Primary prevention of rheumatic fever in Jerusalem schoolchildren. II. Identification of $\beta$-hemolytic streptococci. Israel J. Med. Sci., 4, 809.

HOUSER, H. B. 1969. Report of the 1968 seminar on prophylaxis of streptococcal infections in the Armed Forces. Milit. Med., 134, 1526.

Ivan, I. M., Mihalcou, F., Horhogea, G., Tisu, A., Ionesco, G., Katona, E., and Debeleac, L. 1967. Étude des infections streptococciques dans les collectivités d'enfants de Bucarest, pendant la période 1963-1966. Archs. roum. Path. exp. Microbiol., 26, 627.

Kaplan, E. L., Top, F. H., JR, Dudding, B. A., AND Wannamaker, L. W. 1971. Diagnosis of streptococcal pharyngitis: differentiation of active infection from the carrier state in the symptomatic child. J. Infect. Dis., 123, 490.

Krause, R. M., Rammelkamp, C. H., JR, Denny, F. W., JR, and Wannamaker, L. W. 1962. Studies of the carrier state following infection with group A streptococci. I. Effect of climate. J. Clin. Invest., 41, 568.

LANCEFIELD, REBECCA C. 1933. A serological differentiation of human and other groups of hemolytic streptococci. J. Exp. Med., 57, 571.

Levine, J. I., Chapman, S. S., Guerra, V., CoOper, J., AND Krause, R. M. 1966. Studies on the transmission within families of group A hemolytic streptococci. J. Lab. Clin. Med., 67, 483.

Padula, J. F., FACKLam, R. R., AND Moody, M. 1969. Effect of incubation temperature on T-agglutination typing of Streptococcus pyogenes. Appl. Microbiol., 17, 878.

QuinN, R. W., DenNy, F. W., AND RiLEy, H. D. 1957. Natural occurrence of hemolytic streptococci in normal school children. Amer. J. Publ. Hlth, 47, 995.

RAmmelkamp, C. H., JR 1957. Epidemiology of streptococcal infections. Harvey Lect. 1955-1956, 51, 113.

Rantz, L. A., AND Randall, Elizabeth 1945. A modification of the technic for determination of the antistreptolysin titer. Proc. Soc. Exp. Biol. Med., 59, 22.

Rotta, J., Hejnova, M., Błcová, R., Čư̌ík, B., MíčKová, S., and Salačová, J. 1968. Surveillance of haemolytic streptococcus group and type (Streptococcus pyogenes) distribution over the territory of Czechoslovakia (a five-year study). J. Hyg. Epidem. Microbiol. Immun., 12, 176.

Rotta, J., Krause, R. M., LanCefield, RebecCa C., Everly, W., and Lackland, H. 1971. New approaches for the laboratory recognition of $M$ types of group $A$ streptococci. J. Exp. Med., 134, 1298.

Saslaw, M. S., ANd Streitfeld, M. M. 1956. Group A $\beta$ hemolytic streptococci in relation to rheumatic fever: study of school children in Miami, Florida. Amer. J. Dis. Child., 92, 550 .

Schneider, W. F., Chapman, S., Schultz, V. B., Krause, R. M., and Lancefield, RebecCa C. 1964. Prevention of streptococcal pharyngitis among military personnel and their civilian dependents by mass prophylaxis. New Engl. J. Med., 270, 1205.

Siegel, A. C., Johnson, Eloise E., AND Stollerman, G. H. 1961. Controlled studies of streptococcal pharyngitis in a pediatric population. I. Factors related to the attack rate of rheumatic fever. New Engl. J. Med., 265, 559.

Sorour, A. H., AND El Kholy, A. M. 1969. Rheumatic heart disease survey. I. First survey (October-November, 1966). J. Egypt. Med. Assoc., 52, Supplement 8-9, 1. 
Sorour, A. H., El Kholy, A. M., ANd Shahin, I. 1969a. Assessment of streptococcal infections: antistreptolysin O titers, Qualyub (1966-1967). J. Egypt. Med. Assoc., 52, Supplement 8-9, 53.

Sorour, A. H., El Kholy, A. M., AND Shahin, I. 1969b. Tentative estimate of the prevalence of beta haemolytic streptococci among a rural school children population-Qualyub (January-May, 1967). J. Egypt. Med. Assoc., 52, Supplement 8-9, 105.

SugIhara, C. Y., AND SQUIER, T. L. 1951. Absence of non-specific anamnestic stimulation of antistreptolysin in pneumococcus pneumonia. J. Allergy, 22, 264.

SZITA, J., AND HegYessy, G. 1966. Type distributions of Streptococcus pyogenes strains in the years 1964-1965. Activities within an international survey of the Department of Bacteriology, National Institute of Public Health, Budapest. Acta microbiol. hung., 13, 151.

WANNAmaker, L. W. 1954. The epidemiology of streptococcal infections. In Streptococcal infections, edited by M. McCarty, New York, p. 157.

World Health ORganization 1968. Streptococcal and staphylococcal infections. Technical Report Series, no. 394.

ZIMMERMAN, R. A., AND WILSON, E. 1968. Familial susceptibility to acquisition of group A $\beta$-hemolytic streptococci. Amer. J. Dis. Child., 116, 292. 